Article

\title{
Bio-Based Coating Materials Derived from Acetoacetylated Soybean Oil and Aromatic Dicarboxaldehydes
}

\author{
Zhiyuan Cao, Fei Gao * (D), Jinze Zhao, Xiao Wei, Qian Cheng, Jiang Zhong, Cong Lin, Jinbing Shu, \\ Changqing Fu and Liang Shen * \\ Jiangxi Engineering Laboratory of Waterborne Coating, School of Chemistry and Chemical Engineering, Jiangxi \\ Science \&Technology Normal University, Nanchang 330013, China; 13097208064@163.com (Z.C.); \\ 15936691596@163.com (J.Z.); wxjxkjsfdx@163.com (X.W.); cqzylto@163.com (Q.C.); \\ jiangzhong@jxstnu.com.cn (J.Z.); conglin0127@jxstnu.com.cn (C.L.); jinbingshu@jxstnu.com.cn (J.S.); \\ fuchq0791@jxstnu.com.cn (C.F.) \\ * Correspondence: feigao2016@jxstnu.com.cn (F.G.); liangshen@jxstnu.com.cn (L.S.)
}

Received: 24 August 2019; Accepted: 1 November 2019; Published: 4 November 2019

\begin{abstract}
Bio-based coating materials were prepared from epoxidized soybean oil as a renewable source. Acetoacetylated soybean oil was synthesized by the ring-opened and transesterification reaction of epoxidized soybean oil, and its chemical structure was characterized by nuclear magnetic resonance (NMR), Fourier transform infrared spectroscopy (FTIR), gel permeation chromatography (GPC), and rheometric viscosity analyses. On the basis of acetoacetylated soybean oil, several bio-based coating materials were prepared using different aromatic dicarboxaldehydes (1,2-benzenedialdehyde, 1,3-benzenedialdehyde, 1,4-phthalaldehyde, 4,4'-biphenyldicarboxaldehyde) and characterized. The resulting films possess good performance, including the highest glass transition temperature of $54{ }^{\circ} \mathrm{C}$, a Young's modulus of $24.91 \mathrm{MPa}$, tensile strength of $5.65 \mathrm{MPa}$, and an elongation at break of $286 \%$. Thus, this work demonstrates the Knoevenagel condensation reaction, which is based on soybean oil as a potential newer eco-friendly raw material.
\end{abstract}

Keywords: epoxidized soybean oil; acetoacetylated soybean oil; Knoevenagel condensation reaction; aromatic dicarboxaldehydes

\section{Introduction}

Currently, the development of renewable resources to replace petroleum-based raw materials in the areas of energy and materials is a prominent research field [1-3]. Vegetable oil, as a renewable resource, has attracted considerable attention owing to its low cost, availability, low ecotoxicity, and environmental sustainability [4,5]. Vegetable oils contain unsaturated $\mathrm{C}-\mathrm{C}$ bonds; thus, epoxidation of vegetable oils is commonly employed to graft functional groups by ring-opened reactions [6-8].

Acetoacetate chemistry is an important class of versatile synthetic intermediates of thermoset resins $[9,10]$. The functional groups of acetoacetates allow an efficient crosslinking reaction with various compounds such as isocyanates [11], acrylates (Michael Reaction) [12], amines (enamine formation) [13], and aldehydes. Although there are many synthetic routes for the preparation of covalently bonded acetoacetates into resins, only a few examples have been reported that are applicable for bio-based coating materials. In 2002, the Trumbo group reported a novel bio-based coating material, which is based on an acetoacetylated castor oil and multifunctional amines; the acetoacetylated castor oil was obtained by a transesterification reaction between castor oil and t-butyl acetoacetate, and the properties of the coating were improved by increasing the temperature [14]. In 2012, the Webster group developed a bio-based coating material by amine-acetoacetate reactions between acetoacetylated 
sucrose and multifunctional amines; the coatings exhibited a good balance of properties owing to the degree of enamine alkyl substitution or alkyl chain length [15]. Recently, our group reported a series of bio-based coating materials; the properties of these coatings were controlled by changing the content of acetoacetate groups by thiolene and transesterification reactions [16-19].

The Knoevenagel condensation reaction is as an important $C-C$ bond forming reaction, which can be employed to synthesize many compounds such as herbicides [20], natural products [21], and functional polymers [22]. However, currently, few examples of bio-based coating materials have been reported, which utilized Knoevenagel condensation reactions. In 2019, our group reported the first bio-based coating materials, which were made via the Knoevenagel condensation reaction between acetoacetylated castor oil and aromatic dicarboxaldehydes; however, the coating had inferior mechanical properties [23].

In this paper, we show a novel bio-based coating material, which is based on the reaction between acetoacetylated soybean oil and aromatic dicarboxaldehydes. Acetoacetylated soybean oil was prepared by the ring-opened and transesterification reaction (Scheme 1) [24]. The primary novelties of this paper include the following: (1) Expanding a Knoevenagel condensation reaction base on acetoacetylated soybean oil, (2) obtaining good mechanical/chemical performance, and (3) demonstrating that this method has a very wide application value for renewable plant oils because vegetable oils contain many unsaturated $\mathrm{C}-\mathrm{C}$ bonds and have easy access to epoxy structures.
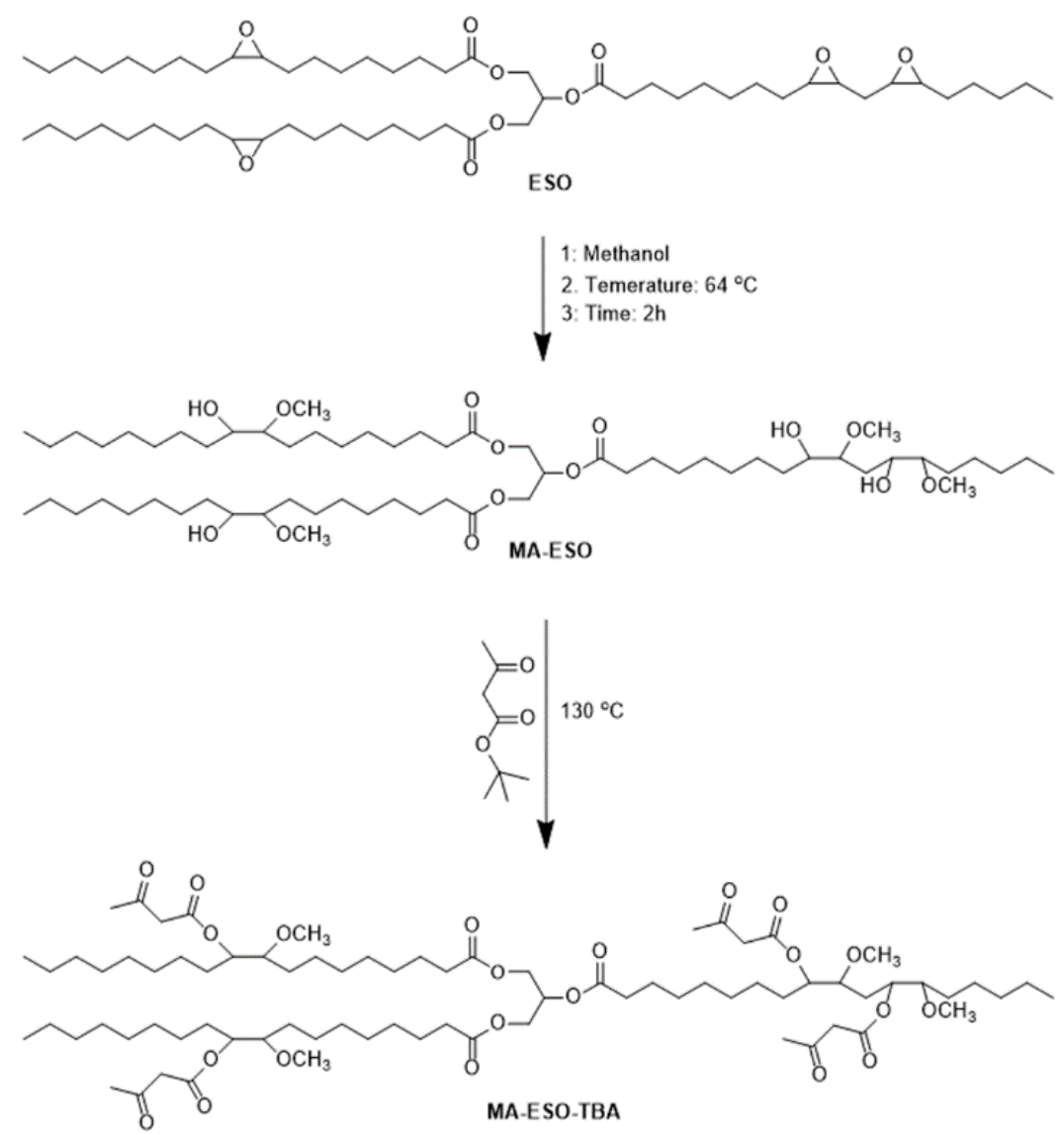

Scheme 1. Synthesis of acetoacetylated soybean oil via the ring-opened and transesterification reactions [24]. 


\section{Materials and Methods}

\subsection{Materials}

Epoxidized soybean oil (ESO), 1,2-benzenedialdehyde, 1,4-phthalaldehyde, 1,3-benzenedialdehyde, t-butyl acetoacetate, tetrafluoro boric acid, and 4,4'-biphenyldicarboxaldehyde were obtained from Sigma Aldrich (Shanghai, China). Ethyl acetate, benzaldehyde, toluene, methanol, tetrahydrofuran (THF), and ethyl acetate were obtained from Xiya Reagent (Chengdu, Sichuang, China). 1,8-Diazabicyclo $(5,4,0)$ undec-7-ene (DBU), 4-dimethylaminopyridine (DMAP), triethylamine, and piperidine were obtained from Beijing Chemical Works (Beijing, China). All materials were used without any further purification.

\subsection{Preparation of Soybean Oil-Based Polyols}

The synthesis of soybean oil-based polyols was performed according to a previously patent reported study [24] (Scheme 1). A mixture of epoxidized soybean oil ( $60 \mathrm{~g}, 62.5 \mathrm{mmol})$, methanol ( $80 \mathrm{~g}$, $2.5 \mathrm{~mol})$, and tetrafluoro boric acid ( $0.1 \mathrm{wt} \%$ of epoxidized soybean oil) was heated in a $250 \mathrm{~mL}$ flask at $64{ }^{\circ} \mathrm{C}$ with magnetic stirring for $2 \mathrm{~h}$. The mixture was quenched to room temperature, extracted by ethyl acetate, and washed with a saturated sodium chloride solution three times. The organic solvent was removed via rotary evaporation, and a colorless oil was obtained with a yield of $84 \% .{ }^{1} \mathrm{H}$ $\operatorname{NMR}\left(\mathrm{CDCl}_{3}, 400 \mathrm{MHz}\right): \delta(\mathrm{ppm})=5.22(\mathrm{~s}, 1 \mathrm{H}), 4.28-4.24(\mathrm{~m}, 2 \mathrm{H}), 4.13-4.12(\mathrm{~m}, 2 \mathrm{H}), 3.99-3.73(\mathrm{~m}$, $4 \mathrm{H}), 3.62-3.56(\mathrm{~m}, 2 \mathrm{H}), 3.37(\mathrm{~s}, 12 \mathrm{H}), 3.33-3.25(\mathrm{~m}, 4 \mathrm{H}), 2.29-2.26(\mathrm{~m}, 6 \mathrm{H}), 2.06-1.96(\mathrm{~m}, 6 \mathrm{H}), 1.85-1.79$ $(\mathrm{m}, 2 \mathrm{H}), 1.58-1.43(\mathrm{~m}, 8 \mathrm{H}), 1.28-1.22(\mathrm{~m}, 62 \mathrm{H})$, and $0.85-0.82(\mathrm{t}, 12 \mathrm{H}) .{ }^{13} \mathrm{C} \mathrm{NMR}\left(\mathrm{CDCl}_{3}, 400 \mathrm{MHz}\right)$ : $\delta(\mathrm{ppm})=173.14,84.30,82.68,72.48,68.92,65.03,62.04,58.10,56.94,56.59,42.7,34.06,33.37,29.88,29.59$, $25.90,25.05,24.75,23.71,14.03,13.92$. GPC (theoretical formula weight $=1089$ ); $M_{\mathrm{n}}=1006, M_{\mathrm{w}}=1057$, PDI $=1.05$. Viscosity: 1.31 Pa s.

\subsection{Preparation of Acetoacetylated Soybean Oil}

The synthesis of acetoacetylated soybean oil was performed according to a previously patent reported study [24] (Scheme 1). A solution of soybean oil-based polyols (63 g, $57.9 \mathrm{mmol}$ ) and t-butyl acetoacetate $(36.64 \mathrm{~g}, 0.232 \mathrm{~mol})$ in a $250 \mathrm{~mL}$ reflux condenser flask was prepared, and then the reaction was heated with magnetic stirring to $110^{\circ} \mathrm{C}$ under nitrogen atmosphere. At $100-110^{\circ} \mathrm{C}$, the liquid of n-butanol was removed, and a yellow oil was obtained with a yield of $85 \% .{ }^{1} \mathrm{H} \mathrm{NMR}\left(\mathrm{CDCl}_{3}\right.$, $400 \mathrm{MHz}): \delta(\mathrm{ppm})=5.21-5.16(\mathrm{~m}, 1 \mathrm{H}), 4.96-4.92(\mathrm{~m}, 4 \mathrm{H}), 4.23-4.20(\mathrm{~m}, 2 \mathrm{H}), 4.09-4.07(\mathrm{~m}, 2 \mathrm{H}), 3.41(\mathrm{~s}$, $4 \mathrm{H}), 3.32(\mathrm{~s}, 12 \mathrm{H}), 2.27-2.23(\mathrm{t}, 6 \mathrm{H}), 2.19(\mathrm{~s}, 12 \mathrm{H}), 2.27-2.23(\mathrm{~m}, 6 \mathrm{H}), 1.55-1.49(\mathrm{~m}, 6 \mathrm{H}), 1.58-1.43(\mathrm{~m}$, $8 \mathrm{H}), 1.22-1.18(\mathrm{~m}, 62 \mathrm{H}), 0.81-0.78(\mathrm{~m}, 12 \mathrm{H}) .{ }^{13} \mathrm{C} \mathrm{NMR}\left(\mathrm{CDCl}_{3}, 400 \mathrm{MHz}\right): \delta(\mathrm{ppm})=199.20,172.09$, 165.76, 80.23, 74.14, 67.78, 60.90, 57.28, 55.78, 49.07, 32.84, 30.76, 28.54, 27.97, 24.39,23.66, 21.44, 12.94 . GPC (theoretical formula weight $=1426$ ); $M_{\mathrm{n}}=1169, M_{\mathrm{w}}=1228$, PDI $=1.05$. Viscosity: 0.61 Pa s.

\subsection{Polymerization of Bio-Based Coating Materials}

The method used for the preparation of the coating materials is as follows (Scheme 2 and Table 1). A mixture of acetoacetylated soybean oil $(1 \mathrm{~g}, 0.7 \mathrm{mmol})$ and crosslinker agent (1,2-benzenedialdehyde, 1,3-benzenedialdehyde, 1,4-phthalaldehyde, 4,4'-biphenyldicarboxaldehyde) $(1.05 \mathrm{mmol}$ ) was dissolved in THF $(3 \mathrm{~mL})$ for $10 \mathrm{~min}$ (owing to the incompatibility of aromatic dicarboxaldehydes with acetoacetylated soybean oil, the coating of materials was performed in a solvent). Then, the catalyst ( $5 \mathrm{wt} \%$ of acetoacetylated soybean oil, DBU) was added to the mixture and mixed for another $10 \mathrm{~min}$. Then, the mixture solution was poured into a poly(tetrafluoroethylene) (PTFE) mould $(8 \mathrm{~cm} \times 8 \mathrm{~cm} \times 1.5 \mathrm{~cm})$ and cured at ambient temperature $\left(25^{\circ} \mathrm{C}\right)$ to obtain a dry coating film (200-300 $\mu \mathrm{m}$ thick). The complete curing reaction was determined by FTIR. 


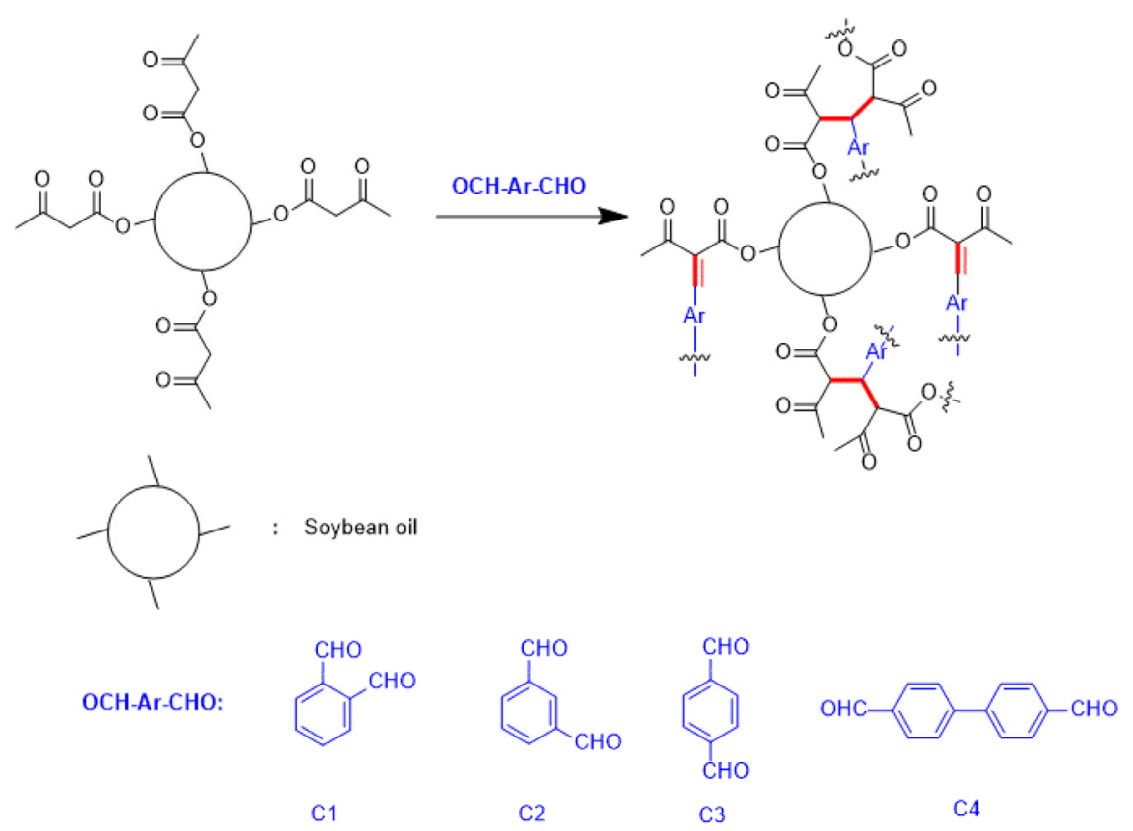

Scheme 2. Synthetic route for coating materials.

Table 1. Sample codes and ratios of materials in the Knoevenagel addition reaction.

\begin{tabular}{cccc}
\hline Sample Code & $\begin{array}{c}\text { Acetoacetylated } \\
\text { Soybean Oil }\end{array}$ & Crosslinker & $\begin{array}{c}\text { Acetoacetate: } \\
\text { Aldehyde Ratio }\end{array}$ \\
\hline P1 & $1 \mathrm{~g}(0.7 \mathrm{mmol})$ & $\begin{array}{c}\text { 1,2-benzenedialdehyde }(\mathrm{C} 1) \\
(0.141 \mathrm{~g}, 1.05 \mathrm{mmol})\end{array}$ & $1: 0.75$ \\
P2 & $1 \mathrm{~g}(0.7 \mathrm{mmol})$ & $\begin{array}{c}\text { 1,3-benzenedialdehyde }(\mathrm{C} 2) \\
(0.141 \mathrm{~g}, 1.05 \mathrm{mmol})\end{array}$ & $1: 0.75$ \\
P3 & $1 \mathrm{~g}(0.7 \mathrm{mmol})$ & $\begin{array}{c}1,4-\text { phthalaldehyde }(\mathrm{C} 3) \\
(0.141 \mathrm{~g}, 1.05 \mathrm{mmol})\end{array}$ & $1: 0.75$ \\
& $1 \mathrm{~g}(0.7 \mathrm{mmol})$ & $\begin{array}{c}4,4^{\prime} \text {-biphenyldicarboxaldehyde } \\
\text { (C4) }(0.221 \mathrm{~g}, 1.05 \mathrm{mmol})\end{array}$ & $1: 0.75$ \\
\hline
\end{tabular}

\subsection{Characterization}

${ }^{1} \mathrm{H}$ and ${ }^{13} \mathrm{C}$ NMR spectra were obtained using a Bruker AV-400 NMR (Bruker, Rheinstetten, Germany) with tetramethylsilane as an internal reference, and deuterated chloroform $\left(\mathrm{CDCl}_{3}\right)$ was used as a solvent. Infrared spectra (IR) were obtained using a Bruker-Vertex70 spectrometer (Bruker, Rheinstetten, Germany) in the attenuated total reflection (ATR) mode. An average of 32 scans of each sample in the range from $3500 \mathrm{~cm}^{-1}$ to $500 \mathrm{~cm}^{-1}$ was obtained. The viscosities of different components and monomer mixtures were measured using a rheometer (Discovery HR-2 rheometer) (TA Instruments, New Castle, DE, USA) at room temperature $\left(25^{\circ} \mathrm{C}\right)$. The drying times for the coatings were determined using a BK Drying Recorder (MICKLE Laboratory Engineering Co. Ltd., Gomshall, United Kingdom), and the results were analyzed using an ASTM D5895-2013. Thermogravimetric analysis (TGA) was performed using a TGA Q50 system (TA Instruments) (TA Instruments Q800, New Castle, DE, USA) at a heating rate of $10{ }^{\circ} \mathrm{C} \mathrm{min}^{-1}$ under an $\mathrm{N}_{2}$ atmosphere flow of $80 \mathrm{~mL} / \mathrm{min}$. Tensile property was determined using a dynamic mechanical analyzer (DMA) (TA Instruments Q800, New Castle, DE, USA) with a cross-headspeed of $10 \mathrm{~mm} / \mathrm{min}$ at $25^{\circ} \mathrm{C}$. Rectangular films of $30 \mathrm{~mm} \times 3 \mathrm{~mm}$ (length $\times$ width) were used for the test, for the final tensile strength and elongation at break of all the films were obtained from average values of at least three replicates of each sample. A dynamic mechanical analyzer (DMA) (TA Instruments Q800, New Castle, DE, USA) in tensile mode at $1 \mathrm{~Hz}$ was used to study the storage moduli and $\tan \delta$ under controlled temperature. The samples were heated from $-30{ }^{\circ} \mathrm{C}$ to $110{ }^{\circ} \mathrm{C}$ at a rate of $5{ }^{\circ} \mathrm{C} \mathrm{min}-1$. Gel permeation chromatography (GPC) was 
performed on a GPC apparatus (Waters 515; Waters, MA, USA) at $25^{\circ} \mathrm{C}$ and a $5 \mu \mathrm{m}$ Styragel HR5E column (Waters, MA, USA). Samples were diluted to $2 \mathrm{mg} \mathrm{mL}^{-1}$ in tetrahydrofuran (THF) for GPC analysis. THF was used as an eluent at a flow rate of $1.0 \mathrm{~mL} \mathrm{~min}^{-1}$. Molecular weights were determined using polystyrene standards (The system was calibrated by narrow polystyrene standards $\left(M_{\mathrm{W}}\right.$ range: 200-300,000 g/mol)). The gel content was determined by fully immersing a known mass $\left(W_{1}\right)$ of cured material in tetrahydrofuran for $24 \mathrm{~h}$ at ambient temperature, followed by filtering, drying, and reweighing of the solid remnants $\mathrm{W}_{2}$. The gel content was calculated by the following equation: $M(\%)$ $=W_{2} / W_{1} \times 100 \%$. The tetrahydrofuran (THF) swelling of film was performed by immersing a known weight $\left(W_{0}\right)$ of the film in a tetrahydrofuran bath, and the towel-dried sample weight $\left(W_{t}\right)$ was obtained. The swelling of the film was calculated by the following equation: $Q(\%)=\left[\left(W_{t}-W_{0}\right) / W_{0}\right] \times 100 \%$.

\section{Results and Discussion}

\subsection{Characterization of AcetoacetylatedSoybean Oil}

In this study, the oxirane group number of ESO used was 4 per molecule, which was confirmed by ${ }^{1} \mathrm{H}$ NMR spectroscopy (Figure S1a, Supporting Information). The chemical structure of the obtained acetoacetylated soybean oil was confirmed by nuclear magnetic resonance spectroscopy (NMR), GPC analyses, and Fourier transform infrared spectroscopy (FTIR). As shown in Figure 1a, the peaks (soybean oil-based polyols, red) at $2.9 \mathrm{ppm}$ (b) and $3.1 \mathrm{ppm}$ (a), which correspond to the oxirane group of epoxidized soybean oil (black), decreased after the ring-opened reaction (by approximately $84 \%$, Figure S1b, Supporting Information), and a new peak (soybean oil-based polyols, red) at $3.6 \mathrm{ppm}$ (c) appeared, which is assigned to the methyl of methanol grafted to epoxidized soybean oil (red). By comparing soybean oil-based polyols (red) to acetoacetylated soybean oil (blue), it was determined that the peaks (soybean oil-based polyols, red) at $3.9 \mathrm{ppm}$ and $4.0 \mathrm{ppm}$ shifted to $4.8-4.9 \mathrm{ppm}$ (acetoacetylated soybean oil), and the peaks corresponding to the new acetoacetate groups appeared at 3.4 and 2.2 ppm (approximately 85\%, in Figure S2b, Supporting Information). In addition, the ${ }^{13} \mathrm{C} N M R$ spectra confirmed that acetoacetylated soybean oil was obtained. The peaks (soybean oil-based polyols, red) attributed to the epoxy bonds in soybean oil (black) at $55 \mathrm{ppm}(\mathrm{g})$ and $56 \mathrm{ppm}$ (h) decreased after the ring-opened reaction, and the new peaks of acetoacetylated soybean oil (blue) at $200 \mathrm{ppm}$ (l) and 165 ppm (m) are shown in Figure 1b. Comparing the gel permeation chromatography (GPC) curves of ESO, soybean oil-based polyols (MA-ESO), and acetoacetylated soybean oil (MA-ESO-TBA) (Figure S3, Supporting Information), the average molecular weight was increased by ring-opened and transesterification reactions.

The FTIR spectra of ESO, soybean oil-based polyols (MA-ESO), acetoacetylated soybean oil (MA-ESO-TBA), and t-butyl acetoacetate are shown in Figure 2. The comparison of ESO (black) and MA-ESO (red) shows that the peak at $823 \mathrm{~cm}^{-1}$ (corresponded to epoxy groups) disappeared and a new peak at $3600-3300 \mathrm{~cm}^{-1}$ (OH group) appeared, which indicates that the ring-opened reaction of epoxidized soybean oil occurred to obtain hydroxyl groups. By comparing MA-ESO (red) and MA-ESO-TBA (blue), the peaks at 1731-1712 $\mathrm{cm}^{-1}$ (the stretching vibration band of $\mathrm{C}=\mathrm{O}$ of $-\mathrm{COCH}_{2} \mathrm{COCH}_{3}$ ) and $1350 \mathrm{~cm}^{-1}\left(\mathrm{C}-\mathrm{O}\right.$ stretch from the ester bond of- $\mathrm{COCH}_{2} \mathrm{COCH}_{3}$ ) were observed. These results indicated that acetoacetylated soybean oil was obtained by the ring-opened and transesterification reaction. 

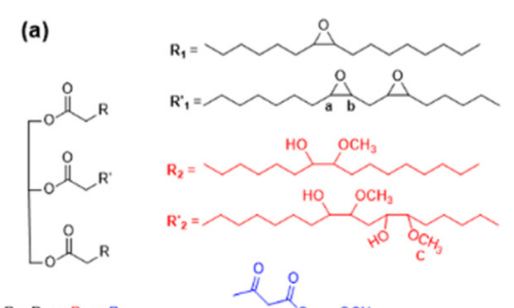

ESO
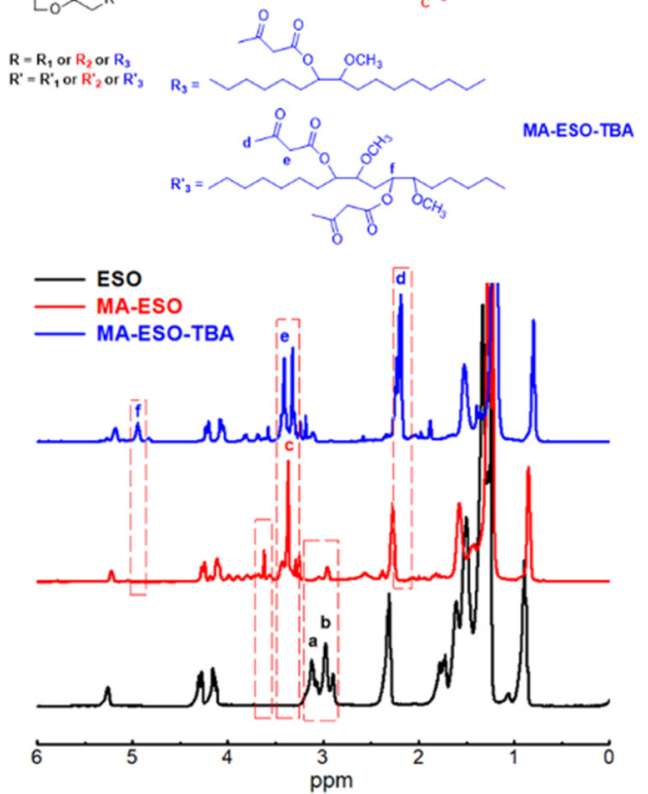

(b)
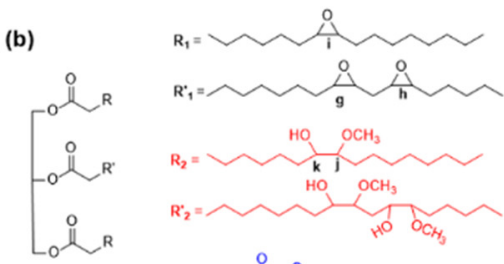

ESO

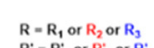

$R=R_{1}$ or $R_{2}$ or $R_{3}$
$R^{\prime}=R_{1}$, or $R_{2}^{\prime}$ or $R_{3}$
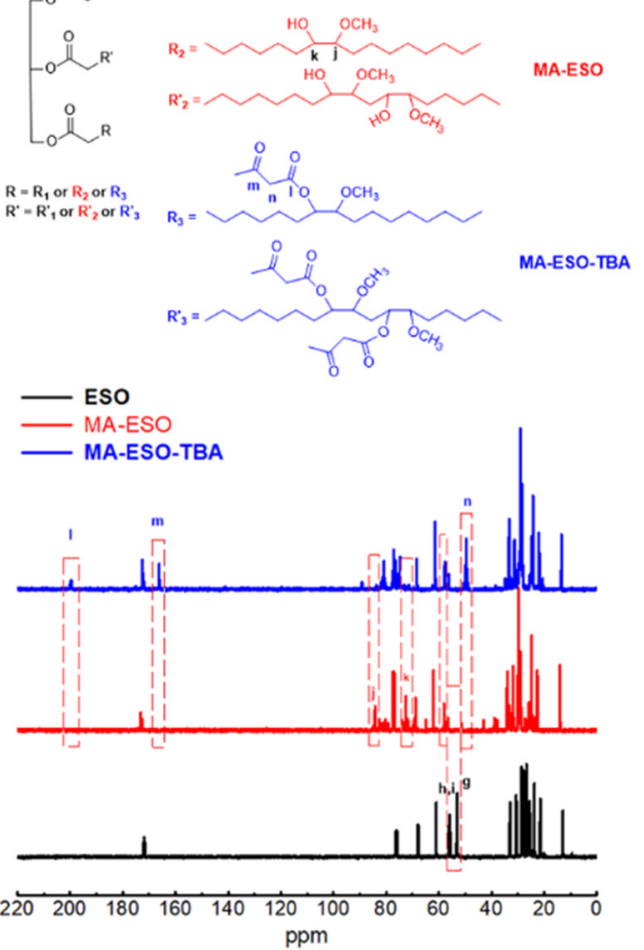

Figure 1. NMR spectra of acetoacetylated soybean oil: $(\mathbf{a}){ }^{1} \mathrm{H}$ NMR spectra and $(\mathbf{b}){ }^{13} \mathrm{C}$ NMR spectra.

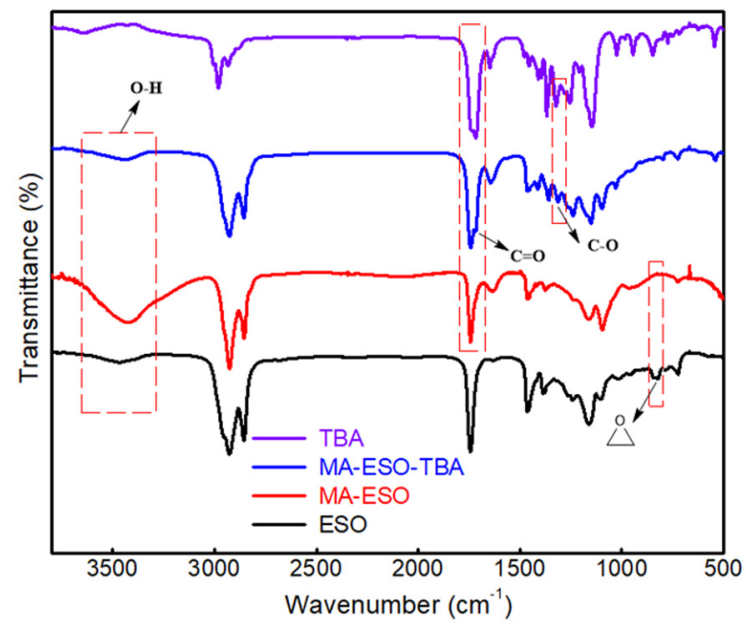

Figure 2. FTIR characterization of acetoacetylated soybean oil.

The viscosities of ESO, soybean oil-based polyols (MA-ESO), and acetoacetylated soybean oil (MA-ESO-TBA) were also measured. As shown in Figure 3, the viscosity increased from $0.14 \mathrm{~Pa} \mathrm{~s}$ (epoxidized soybean oil, black) to 1.31 Pa s (soybean oil-based polyols, red) after the ring-opened reaction. The main reason for thisis the increased intermolecular hydrogen bonding by the ring-opened reaction.Then, after the transesterification reaction (from soybean oil-based polyols to acetoacetylated soybean oil), the viscosity decreased from $1.31 \mathrm{~Pa}$ s to $0.61 \mathrm{~Pa} \mathrm{~s}$, due to the disappeared hydrogen bonding interactions by the transesterification reaction [25]. However, compared to ESO and MA-ESO-TBA, the viscosity of MA-ESO-TBA was increased.The main reason for this may be that the molecular weight of MA-ESO-TBA wasincreased [26]. 


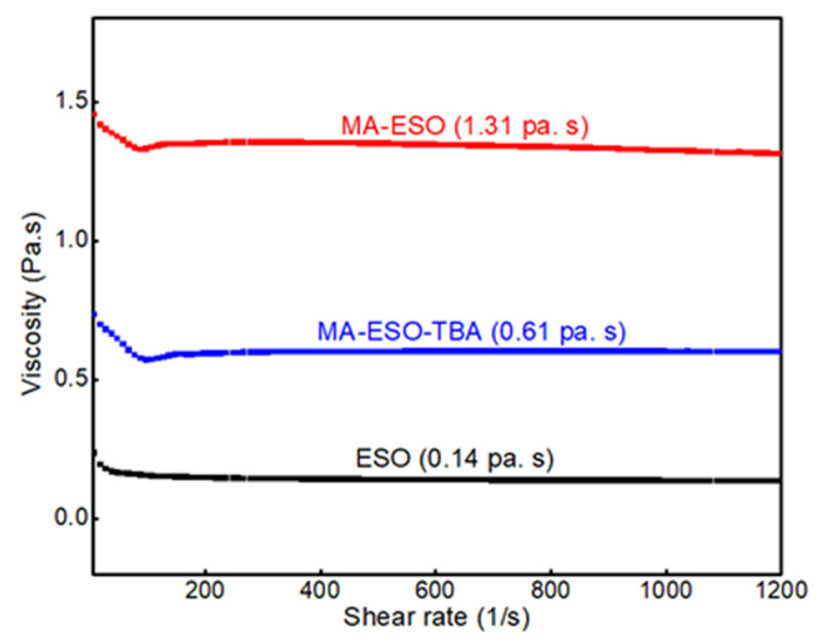

Figure 3. Rheological viscosity versus shear rate for epoxidized soybean oil (ESO), soybean oil-based polyols (MA-ESO), and acetoacetylated soybean oil (MA-ESO-TBA).

\subsection{Characterization of the Films}

In the initial study, we chose acetoacetylated soybean oil (MA-ESO-TBA) and 1,2-benzenedialdehyde as model starting materials to examine these coating materials, and the ratio of acetoacetate and aldehyde groups was 1:0.75, as previously reported [23]. As shown in Table 2, the film can be cured with piperidine as a catalyst (3 wt \%) in $40 \mathrm{~h}$ (Table 2, Entry 1) and the curing time with DMAP (3 wt \%) as a catalyst was $20 \mathrm{~h}$ (Table 2, Entry 2). When 1,8-diazabicyclo $(5,4,0)$ undec-7-ene (DBU) ( $3 \mathrm{wt} \%$ ) was used as acatalyst, the curing time could be reduced to $8 \mathrm{~h}$ with a good gel content of $83 \%$ (Table 2, Entry 3). Furthermore, we optimized the catalyst loading (DBU) and found that $5 \mathrm{wt} \%$ of DBU achieved the best curing time of $3.5 \mathrm{~h}$, with a gel content of up to $88 \%$.

Table 2. Optimization of the preparation reaction conditions.

\begin{tabular}{ccccc}
\hline Entry & Catalyst & CuringTime $^{\text {a }}$ (h) & Solvent-Swelling (\%) & Gel Content (\%) \\
\hline 1 & Piperidine $(3 w t \%)$ & $40 \mathrm{~h}$ & 315 & 70 \\
2 & DMAP $(3 w \mathrm{w} \%)$ & $20 \mathrm{~h}$ & 302 & 72 \\
4 & DBU $(3 \mathrm{wt} \%)$ & $8 \mathrm{~h}$ & 270 & 83 \\
5 & DBU $(5 \mathrm{wt} \%)$ & $3 \mathrm{~h}$ & 220 & 88 \\
6 & DBU $(8 \mathrm{wt} \%)$ & $2.8 \mathrm{~h}$ & 225 \\
\hline \multicolumn{5}{c}{ a Dry through curing time. }
\end{tabular}

In order to explanate the Knoevenagel reaction mechanism of this cured film, we used ethyl acetate and benzaldehyde as model materials, $5 \mathrm{wt} \%$ of DBU as catalyst (similar reaction condition based on the best optimize reaction condition), and found that two types of compounds were obtained and determined by NMR (Model reaction section, Supporting Information). The result showed that the acetoacetyloxy group can react with the aldehyde group and obtained two structure types at molar ratios of 1:0.75. Similar Knoevenagel reaction mechanisms have been reported in the Raju group [27].

After the optimization of reaction conditions, four coating (P1, P2, P3, and P4) films were obtained by different crosslinkers ( $\mathrm{C} 1, \mathrm{C} 2, \mathrm{C} 3$ and $\mathrm{C} 4$, respectively). The characterization data of four coating films are displayed in Table 3. Comparison of the four films shows that all films had good gel content (87-90\%). Thesolvent-swelling (in THF) decreasedfrom $220 \%$ to $130 \%$; the main reason for this was that the crosslinking density from P1 to P4 is gradually increased. 
Table 3. Films made with different crosslinkers.

\begin{tabular}{|c|c|c|c|c|c|c|}
\hline \multirow{2}{*}{ Sample } & \multicolumn{4}{|c|}{ Curing Time (h) } & \multirow{2}{*}{$\begin{array}{c}\text { Solvent-Swelling } \\
(\%)\end{array}$} & \multirow{2}{*}{$\begin{array}{l}\text { Gel Content } \\
\text { (\%) }\end{array}$} \\
\hline & Set to Touch & Tack Free & Dry Hard & Dry Through & & \\
\hline P1 & 1.1 & 2.1 & 2.6 & $3 \mathrm{~h}$ & 220 & 88 \\
\hline P2 & 1.2 & 3.2 & 4.6 & $5.5 \mathrm{~h}$ & 175 & 90 \\
\hline P3 & 1.5 & 3.3 & 5.0 & $6 \mathrm{~h}$ & 156 & 92 \\
\hline P4 & 1.6 & 4.1 & 5.6 & $6.5 \mathrm{~h}$ & 130 & 87 \\
\hline
\end{tabular}

\subsubsection{FTIR Characterization of Films}

These coating films were characterized by FTIR, and the spectra are shown in Figure 4. Acetoacetylated soybean oil spectrum was compared with those of the samples C1 and P1, C2 and $\mathrm{P} 2, \mathrm{C} 3$ and $\mathrm{P} 3$, and $\mathrm{C} 4$ and $\mathrm{P} 4$, which were produced by the Knoevenagel addition reaction. The peaks for $\mathrm{P} 1, \mathrm{P} 2, \mathrm{P} 3$, and $\mathrm{P} 4$ at $2745 \mathrm{~cm}^{-1}$ (a, -CHO stretching frequency) decreased after curing, and the gels of the coating materials (P1, P2, P3, and P4) had characteristic absorption peaks of benzene rings at $1600 \mathrm{~cm}^{-1}$ (b) and $1381 \mathrm{~cm}^{-1}$ (c). These results indicated that four coating films were successfully obtained. Similar reactions between aldehyde and acetoacetyloxy groups have been previously reported $[23,27,28]$.

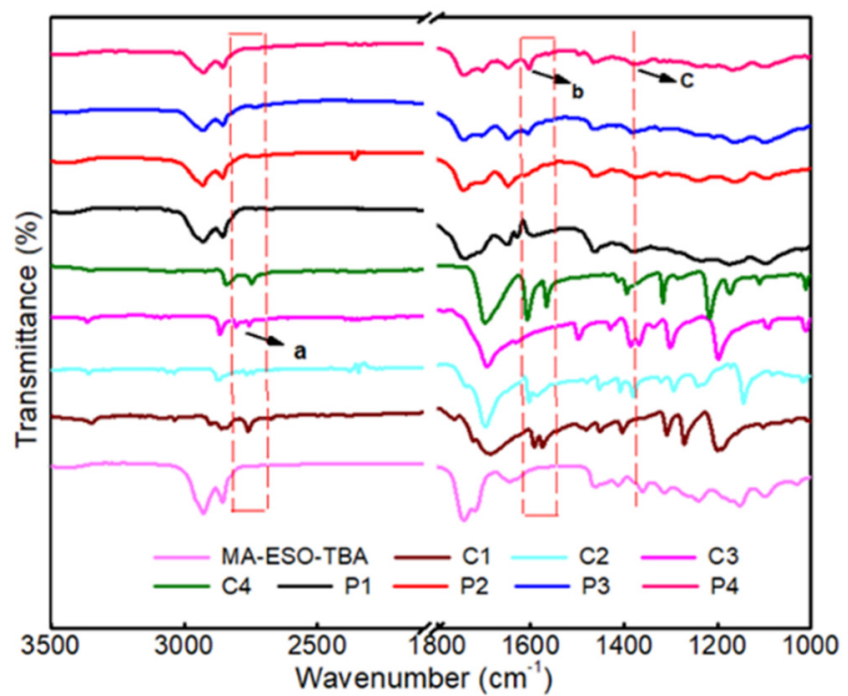

Figure 4. FTIR spectra of the four films (P1, P2, P3, and P4), four crosslinkers (C1, C2, C3, and C4) and acetoacetylated soybean oil, and the peaks of a is $\mathrm{CHO}$ stretching frequency, $\mathrm{b}$ and $\mathrm{c}$ are the peaks of benzene rings.

\subsubsection{Mechanical Properties}

Figure 5 shows the storage modulus and loss factor $(\tan \delta)$ as a function of temperature for the four films with different crosslinkers (C1, C2, C3, and C4). It was observed that all films exhibited similar trends of the storage modulus ( $\left.\mathrm{E}^{\prime}\right)$ values, as follows: Storage modulus decreased at a certain temperature and then stabilized (Figure $5 a$ ). The loss factors $(\tan \delta)$ of the four films are shown in Figure $5 \mathrm{~b}$. Specifically, only one peak is observed, which indicates that the four films exhibit homogeneous properties. The crosslinking density can be calculated by the equation $V_{\mathrm{e}}=\mathrm{E}^{\prime} / 3 \mathrm{RT}$, which has been previously reported [29-31]. The crosslinking density, $T_{\mathrm{g}}$, and storage modulus of the four films (P1-P4) are shown in Table 4. Compared to the four films, P4 has the higher $T_{\mathrm{g}}$ and crosslinking density. The main reason for this may be that the crosslinker $\mathrm{C} 4$ has alower steric hindrance structure. 

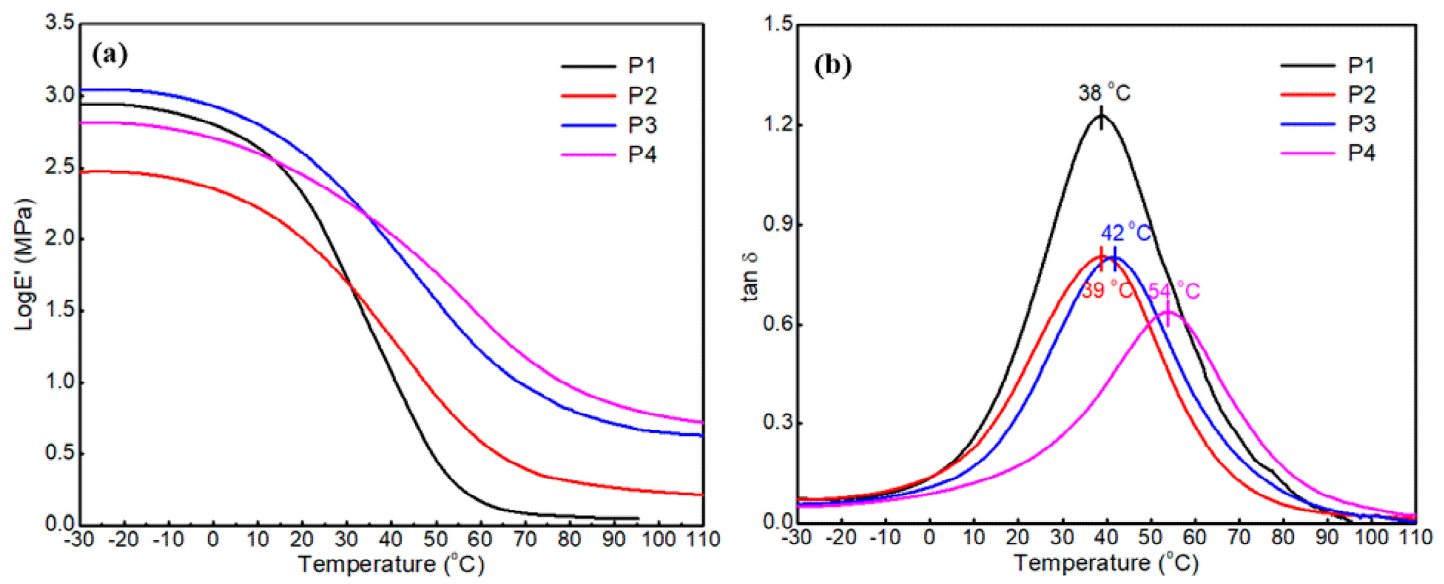

Figure 5. Dynamic mechanical analysis (DMA) of the four films: (a) Storage modulus and (b) loss factor $(\tan \delta)$ as a function of temperature of the four films.

Table 4. Mechanical properties of the films.

\begin{tabular}{cccccccc}
\hline $\begin{array}{c}\text { Sample } \\
\text { Code }\end{array}$ & Tan $\delta$ & $\mathbf{T}_{\mathbf{g}}(\tan \delta)$ & $\begin{array}{c}\mathbf{E}^{\prime} \text { at } \boldsymbol{T}_{\mathbf{g}}+ \\
\mathbf{5 0}{ }^{\circ} \mathbf{C} \\
\mathbf{( M P a )}\end{array}$ & $\begin{array}{c}\text { Crosslinking } \\
(\mathbf{V e}) \\
\left(\mathbf{m o l} / \mathbf{m}^{3}\right)\end{array}$ & $\begin{array}{c}\text { Young's } \\
\text { Modulus } \\
\mathbf{( M P a})\end{array}$ & $\begin{array}{c}\text { Stress at } \\
\text { Break } \\
(\mathbf{M P a})\end{array}$ & $\begin{array}{c}\text { Elongation } \\
\text { at Break }\end{array}$ \\
\hline P1 & 1.22 & $38^{\circ} \mathrm{C}$ & 0.13 & 14.34 & $2.76 \pm 0.7$ & $1.44 \pm 0.05$ & $286 \pm 8$ \\
P2 & 0.81 & $39^{\circ} \mathrm{C}$ & 0.32 & 35.46 & $6.27 \pm 1.6$ & $3.54 \pm 0.07$ & $164 \pm 6$ \\
P3 & 0.79 & $42^{\circ} \mathrm{C}$ & 0.79 & 88.82 & $15.07 \pm 2.7$ & $3.85 \pm 0.1$ & $142 \pm 3$ \\
P4 & 0.63 & $54^{\circ} \mathrm{C}$ & 0.85 & 90.44 & $24.91 \pm 3.9$ & $5.65 \pm 0.13$ & $71 \pm 1$ \\
\hline
\end{tabular}

The stress-strain behaviours of the four films are shown in Figure 6. By comparing P1, P2, and P3, it was determined that as the structural steric resistance of the crosslinkers $(\mathrm{C} 1, \mathrm{C} 2$, and $\mathrm{C} 3$, respectively) decreased, the crosslinking density and mechanical properties (elongation at break, Young's modulus, and tensile strength) gradually increased (Table 4). Furthermore, P4 has the highest mechanical properties (elongation at break, Young's modulus, and tensile strength), due to that P4 has the highest crosslinking density.
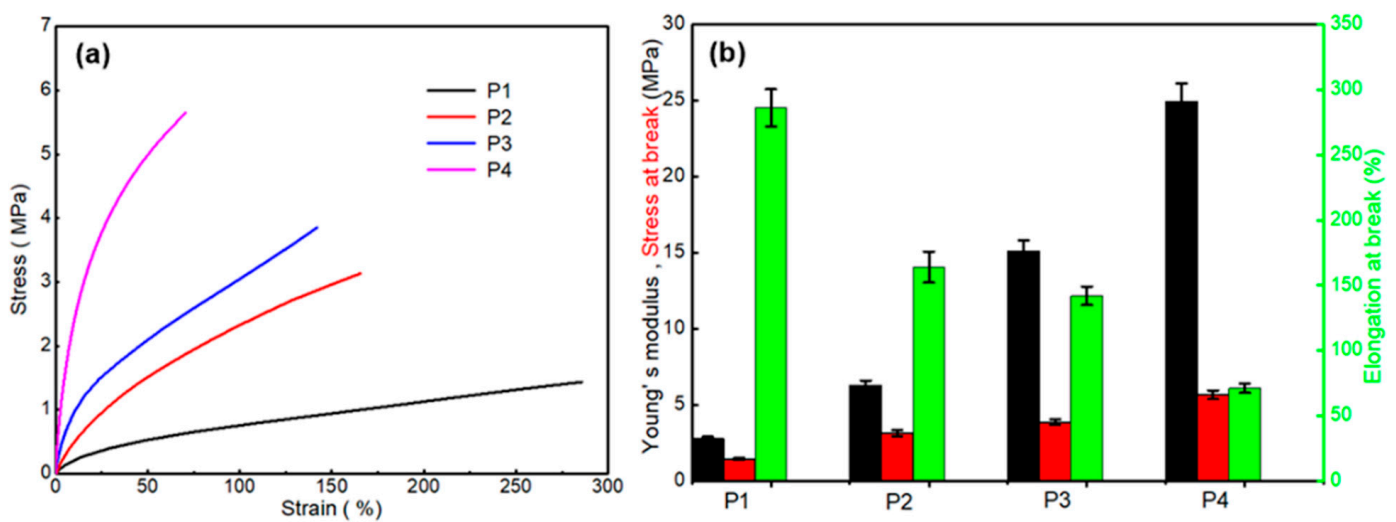

Figure 6. Stress-strain curves for the films, (a) DMA curves of these films (b) Young's Modulus, stress at Break, and tensile strength of these cured samples.

\subsubsection{Thermal Stability}

Figure 7 shows TGA curves and their derivative curves for the four films, and the $T_{10}, T_{50}$, and $T_{\text {max }}$ data are summarized in Table 5. The thermal degradation profile of the four films shows two rapid thermal degradation steps at approximately $160-280{ }^{\circ} \mathrm{C}$ and $280-550{ }^{\circ} \mathrm{C}$. The unstable ester groups were released at approximately $160-280^{\circ} \mathrm{C}$ [32], and the chain scission of the corresponding 
polymer skeleton occurred at approximately $280-550{ }^{\circ} \mathrm{C}$ [33]. By comparing the $T_{10}, T_{50}$, and $T_{\max }$ data of the four films, it was determined that the thermal stability of these films follows the order of $\mathrm{P} 4>\mathrm{P} 3>\mathrm{P} 2>\mathrm{P} 1$. The glass transition temperature $\left(T_{\mathrm{g}}\right)$ values determined from the differential scanning calorimetry (DSC) thermograms are shown in Figure S4 (in Supporting Information) and Table 5. Three films (P1, P2, and P3) have similar $T_{g}$, and P4 has a higher $T_{g}$. These results are similar to the glass transition temperature $\left(T_{\mathrm{g}}\right)$ determined by DMA analysis.
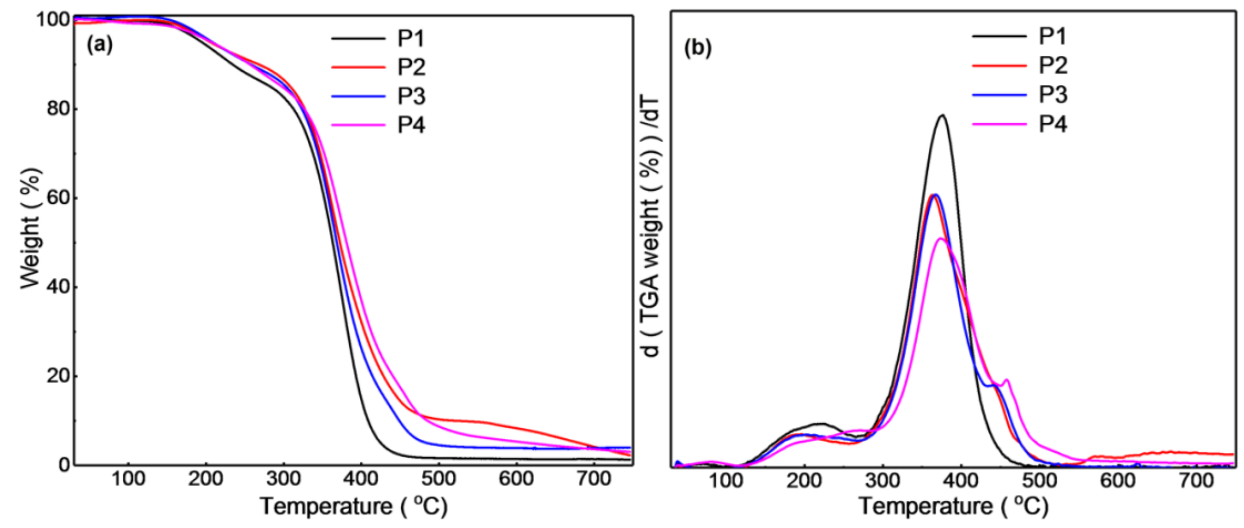

Figure 7. Curves (a) and DTGA curves (b) for the four films.

Table 5. Thermal properties of the four films.

\begin{tabular}{ccccc}
\hline \multirow{2}{*}{ Sample } & \multicolumn{3}{c}{ TGA in Nitrogen $\left({ }^{\circ} \mathbf{C}\right)$} & \multirow{2}{*}{ DSC $\boldsymbol{T}_{\mathbf{g}}\left({ }^{\circ} \mathbf{C}\right)$} \\
\cline { 2 - 4 } & $\boldsymbol{T}_{\mathbf{1 0}}$ & $\boldsymbol{T}_{\mathbf{5 0}}$ & $\boldsymbol{T}_{\max }$ & \\
\hline P1 & 234 & 363 & 449 & 16 \\
P2 & 268 & 372 & 473 & 14 \\
P3 & 257 & 368 & 485 & 17 \\
P4 & 256 & 381 & 531 & 34 \\
\hline
\end{tabular}

$T_{10}, T_{50}$, and $T_{\max }$ represent the temperatures that correspond to the mass loss of $10 \mathrm{wt} \%, 50 \mathrm{wt} \%$, and the maximum mass loss, respectively.

\section{Conclusions}

A novel bio-based coating material was developed using the Knoevenagel condensation reaction between acetoacetylated soybean oil and aromatic dicarboxaldehydes. Acetoacetylated soybean oilwas synthesizedat ambient curing conditions, and its chemical structure was determined by NMR, FTIR, GPC, and viscosity characterization. Then, four bio-based coating materials were prepared by acetoacetylated soybean oil and aromatic dicarboxaldehydes. These coating materials were characterized by Fourier transform infrared spectroscopy. Thermal and mechanical properties were characterized by DSC, TGA, and DMA. These coating materials exhibit good mechanical/chemical performance. The characteristics of this novel system demonstrate theapplicability of theKnoevenagel condensation reaction for soybean oil as a new eco-friendly raw material.

Supplementary Materials: The following are available online at http://www.mdpi.com/2073-4360/11/11/1809/s1, Figure S1 ${ }^{1} \mathrm{H}$ NMR spectra of (a) epoxy soybean oil (ESO) and (b) soybean oil-based polyols (MA-ESO), Figure S2 ${ }^{1} \mathrm{H}$ NMR spectra of (a) soybean oil-based polyols (MA-ESO) and (b) acetoacetylated soybean oil (MA-ESO-TBA). Figure S3 The GPC of acetoacetylated soybean oil, Figure S4 DSC curves indicate the glass transition temperature $\left(T_{\mathrm{g}}\right)$ of the four films. Figure S5 ${ }^{1} \mathrm{H}$ NMR $(400 \mathrm{M})$ spectrum of epoxy soybean oil (ESO), Figure S6 ${ }^{13} \mathrm{C}$ NMR $(400 \mathrm{M})$ spectrum of epoxy soybean oil (ESO),Figure S7 ${ }^{1} \mathrm{H}$ NMR (400 M) spectrum of soybean oil-based polyols (MA-ESO), Figure S8 ${ }^{13} \mathrm{C}$ NMR (400 M) spectrum of soybean oil-based polyols (MA-ESO), Figure S9 ${ }^{1} \mathrm{H}$ NMR $(400 \mathrm{M})$ spectrum of acetoacetylated soybean oil (MA-ESO-TBA), Figure S10 ${ }^{13} \mathrm{C}$ NMR (400 M) spectrum of 
acetoacetylated soybean oil (MA-ESO-TBA), Figure S111H NMR (400 M) spectrum of compound A, Figure S12 ${ }^{13}$ C NMR (400 M) spectrum of compound A.Table S1. Properties of the acetoacetylated soybean oil.

Author Contributions: Conceptualization, F.G. and Z.C.; methodology, Z.C. and J.Z. (Jinze Zhao); software, X.W.; formal analysis, Q.C. and J.Z. (Jiang Zhong); investigation, C.L. and J.S.; resources, F.G. and L.S.; data curation, C.F.; writing —original draft preparation, F.G. and Z.C.; writing-review and editing, F.G. and L.S.

Funding: This research was funded by the Program for the NSFC of China (No. 51963010, 21704036, 21905121), Science Funds of the Education Office of Jiangxi Province (No. GJJ170658), and the Science Funds of Jiangxi Province (No. 20171BAB216019, No. 20181BAB206016).

Conflicts of Interest: The authors declare no conflict of interest.

\section{References}

1. Dai, J.; Peng, Y.; Teng, N.; Liu, Y.; Liu, C.; Shen, X.; Mahmud, S.; Zhu, J.; Liu, X. High-Performing and Fire-Resistant Biobased Epoxy Resin from Renewable Sources. ACS Sustain. Chem. Eng. 2018, 6, 7589-7599. [CrossRef]

2. Yao, K.; Tang, C. Controlled Polymerization of Next-Generation Renewable Monomers and Beyond. Macromolecules 2013, 46, 1689-1712. [CrossRef]

3. Allauddin, S.; Narayan, R.; Raju, K.V.S.N. Synthesis and Properties of Alkoxysilane Castor Oil and Their Polyurethane/Urea-Silica Hybrid Coating Films. ACS Sustain. Chem. Eng. 2013, 1, 910-918. [CrossRef]

4. Chen, R.Q.; Zhang, C.Q.; Kessler, M.R. Polyols and Polyurethanes Prepared from Epoxidized Soybean Oil Ring-Opened by Polyhydroxy Fatty Acids with Varying OH Numbers. J. Appl. Polym. Sci. 2015, 132. [CrossRef]

5. Tsujimoto, T.; Takayama, T.; Uyama, H. Biodegradable Shape Memory Polymeric Material from Epoxidized Soybean Oil and Polycaprolactone. Polymers 2015, 7, 2165-2174. [CrossRef]

6. Biswas, A.; Sharma, B.K.; Willett, J.L.; Advaryu, A.; Erhan, S.Z.; Cheng, H.N. Azide Derivatives of Soybean Oil and Fatty Esters. J. Agric. Food Chem. 2008, 56, 5611-5616. [CrossRef]

7. Tan, J.; Liu, B.; Fu, Q.; Wang, L.; Xin, J.; Zhu, X. Role of the Oxethyl Unit in the Structure of Vegetable Oil-Based Plasticizer for PVC: An Efficient Strategy to Enhance Compatibility and Plasticization. Polymers 2019, 11, 779. [CrossRef]

8. Dworakowska, S.; Bogdal, D.; Prociak, A. Microwave-Assisted Synthesis of Polyols from Rapeseed Oil and Properties of Flexible Polyurethane Foams. Polymers 2012, 4, 1462-1477. [CrossRef]

9. Wright, T.; Tomkovic, T.; Hatzikiriakos, S.G.; Wolf, M.O. Photoactivated Healable Vitrimeric Copolymers. Macromolecules 2019, 52, 36-42. [CrossRef]

10. Sims, M.B.; Lessard, J.J.; Bai, L.; Sumerlin, B.S. Functional Diversification of Polymethacrylates by Dynamic $\beta$-Ketoester Modification. Macromolecules 2018, 51, 6380-6386. [CrossRef]

11. Liu, Z.; Yu, C.; Zhang, C.; Shi, Z.; Yin, J. Revisiting Acetoacetyl Chemistry to Build Malleable Cross-Linked Polymer Networks via Transamidation. ACS Macro Lett. 2019, 8, 233-238. [CrossRef]

12. Whittington, C.P.; Daily, L.A.; Miller, K.M. Crosslinked imidazolium-containing polyester networks containing a pendant imidazolium group: Swelling studies and thermal properties. Polymer 2014, 55, 3320-3329. [CrossRef]

13. Denissen, W.; De Baere, I.; Van Paepegem, W.; Leibler, L.; Winne, J.; Du Prez, F.E. Vinylogous Urea Vitrimers and Their Application in Fiber Reinforced Composites. Macromolecules 2018, 51, 2054-2064. [CrossRef]

14. Trevino, A.S.; Trumbo, D.L. Acetoacetylated castor oil in coatings applications. Prog. Org. Coat. 2002, 44, 49-54. [CrossRef]

15. Xiao, P.; Nelson, T.J.; Webster, D.C. Novel biobased dual-cure coating system. Prog. Org. Coat. 2012, 73, 344-354.

16. Xu, D.; Cao, Z.; Wang, T.; Zhao, J.; Zhong, J.; Xiong, P.; Wang, J.; Gao, F.; Shen, L. Effect of the Ratio of Acetylacetate Groups on the Properties of a Novel Plant-Based Dual-Cure Coating System. ACS Omega 2019, 4, 11173-11180. [CrossRef]

17. Wang, T.; Wang, J.; He, X.; Cao, Z.; Xu, D.; Gao, F.; Zhong, J.; Shen, L. An Ambient Curable Coating Material Based on the Michael Addition Reaction of Acetoacetylated Castor Oil and Multifunctional Acrylate. Coatings 2019, 9, 37. [CrossRef] 
18. Zuo, H.; Cao, Z.; Shu, J.; Xu, D.; Zhong, J.; Zhao, J.; Wang, T.; Chen, Y.; Gao, F.; Shen, L. Effect of structure on the properties of ambient-cured coating films prepared via a Michael addition reaction based on an acetoacetate-modified castor oil prepared by thiol-ene coupling. Prog. Org. Coat. 2019, 135, 27-33. [CrossRef]

19. Xu, D.; Cao, Z.; Wang, T.; Zhong, J.; Zhao, J.; Gao, F.; Luo, X.; Fang, Z.; Cao, J.; Xu, S.; et al. An ambient-cured coating film obtained via a Knoevenagel and Michael addition reactions based on modified acetoacetylated castor oil prepared by a thiol-ene coupling reaction. Prog. Org. Coat. 2019, 135, 510-516. [CrossRef]

20. Kastl, J.; Braun, J.; Prestel, A.; Möller, H.M.; Huhn, T.; Mayer, T.U. Mad2 Inhibitor-1 (M2I-1): A Small Molecule Protein-Protein Interaction Inhibitor Targeting the Mitotic Spindle Assembly Checkpoint. ACS Chem. Biol. 2015, 10, 1661-1666. [CrossRef]

21. Peña, R.; Martín, P.; Feresin, G.E.; Tapia, A.; Machín, F.; Estévez-Braun, A. Domino Synthesis of Embelin Derivatives with Antibacterial Activity. J. Nat. Prod. 2016, 79, 970-977. [CrossRef] [PubMed]

22. Bi, S.; Lan, Z.A.; Paasch, S.; Zhang, W.; He, Y.; Zhang, C.; Liu, F.; Wu, D.; Zhuang, X.; Brunner, E. Substantial Cyano-Substituted Fully sp2-Carbon-Linked Framework: Metal-Free Approach and Visible-Light-Driven Hydrogen Evolution. Adv. Funct. Mater. 2017, 27, 1703146. [CrossRef]

23. He, X.; Zhong, J.; Cao, Z.; Wang, J.; Gao, F.; Xu, D.; Shen, L. An exploration of the Knoevenagel condensation to create ambient curable coating materials based on acetoacetylated castor oil. Prog. Org. Coat. 2019, 129, 21-25. [CrossRef]

24. Campbell, C.J.; Lewandowski, K.M.; Owusu-Adom, K. Curable and Cured Compositions. U.S. Patent 9,290,683 B2, 22 March 2016.

25. Yin, Y.; Ma, L.; Wen, S.; Luo, J. Fracture of the Intermolecular Hydrogen Bond Network Structure of Glycerol Modified by Carbon Nanotubes. J. Phys. Chem. C 2018, 122, 19931-19936. [CrossRef]

26. Yadav, S.K.; Hu, F.; La Scala, J.J.; Palmese, G.R. Toughening Anhydride-Cured Epoxy Resins Using Fatty Alkyl-Anhydride-Grafted Epoxidized Soybean Oil. ACS Omega 2018, 3, 2641-2651. [CrossRef]

27. Allauddin, S.; Jena, K.K.; Mishra, A.K.; Radhika, K.R.; Narayan, R.; Raju, K.V.S.N. Synthesis \& characterization of benzaldehyde modified acetoacetylated polyesters for polyurethane/urea coatings. Prog. Org. Coat. 2012, 75, 131-138.

28. Dalessandro, E.V.; Collin, H.P.; Guimarães, L.G.L.; Valle, M.S.; Pliego, J.R. Mechanism of the Piperidine-Catalyzed Knoevenagel Condensation Reaction in Methanol: The Role of Iminium and Enolate Ions. J. Phys. Chem. B 2017, 121, 5300-5307. [CrossRef]

29. Mehta, B.; Watt, P.; Soucek, M.D.; Pugh, C. Moderate Temperature Curing of Plant Oils with Bismaleimides via the Ene Reaction. Ind. Eng. Chem. Res. 2016, 55, 11727-11735. [CrossRef]

30. Zhang, Y.; Li, Y.; Guan, Q.; Liang, G.; Gu, A. Developing self-healable and antibacterial polyacrylate coatings with high mechanical strength through crosslinking by multi-amine hyperbranched polysiloxane via dynamic vinylogous urethane. J. Mater. Chem. A 2017, 5, 16889-16897. [CrossRef]

31. Zhang, C.; Madbouly, S.A.; Kessler, M.R. Biobased Polyurethanes Prepared from Different Vegetable Oils. ACS Appl. Mater. Interfaces 2015, 7, 1226-1233. [CrossRef]

32. Fu, C.; Liu, J.; Xia, H.; Shen, L. Effect of structure on the properties of polyurethanes based on aromatic cardanol-based polyols prepared by thiol-ene coupling. Prog. Org. Coat. 2015, 83, 19-25. [CrossRef]

33. Feng, Y.; Liang, H.; Yang, Z.; Yuan, T.; Luo, Y.; Li, P.; Yang, Z.; Zhang, C. A Solvent-Free and Scalable Method to Prepare Soybean-Oil-Based Polyols by Thiol-Ene Photo-Click Reaction and Biobased Polyurethanes Therefrom. ACS Sustain. Chem. Eng. 2017, 5, 7365-7373. [CrossRef]

(C) 2019 by the authors. Licensee MDPI, Basel, Switzerland. This article is an open access article distributed under the terms and conditions of the Creative Commons Attribution (CC BY) license (http://creativecommons.org/licenses/by/4.0/). 